\title{
Evaluation of Ph Value Changes That Intracanal Medicaments Cause to the Surrounding Periapical Medium, And Nvestigation of the Effects of an Acidic Environment to These Ph Value Changes - An In Vitro Study
}

\author{
Dr.Jayasudha ${ }^{1}$, Dr.Nandlal ${ }^{2}$, Dr. Baswaraj ${ }^{3}$ \\ ${ }^{1,2}$ (Department of pedodontics and preventive dentistry, JSS dental college, JSS university, India) \\ ${ }^{3}$ (Department of orthodontics, GDC, Bangalore, India)
}

\begin{abstract}
The purpose of this in vitro study was to test the $p H$ changes that occurred over a period of 7 days using calcium hydroxide, Metapex and Ledermix \& Calcium hydroxide combination and to compare the effect of contamination in a simulated periapical environment. The materials were filled in extracted premolar roots, which were suspended in individual vials containing distilled water at a $\mathrm{pH}$ of 7.4. Digital pH-meter was used to measure the $\mathrm{pH}$ of different groups at half an $\mathrm{hr}, 1 \mathrm{hr}, 4 \mathrm{hr}, 1$ day, 2 days 3 days \& 7 days after immersion of the specimens. The mean $\mathrm{pH}$ was found for all groups and statistical analysis was carried out using repeated Measure ANOVA. Combination of medicaments did affect the $\mathrm{pH}$ of calcium hydroxide significantly. Calcium hydroxide was found to significantly raise the $\mathrm{pH}$ of the surrounding medium with and without contamination of root canals compared to combination medicaments. Therefore calcium hydroxide is an effective choice in clinical practice where seepage of pus into the root canal between appointments.
\end{abstract}

Keywords: Calcium hydroxide, Combination, Contamination, Intracanal medicaments, $p H$, Periapical

\section{Introduction}

Calcium hydroxide is the preferred material for an intracanal dressing because of its favorable antimicrobial action. One of the main benefits of calcium hydroxide-based materials is the high $\mathrm{pH}$ they impart on the surrounding environment, the increase in $\mathrm{pH}$ in the surrounding tissues results mainly from the release of hydroxyl ions ${ }^{1}$.

With the exception of calcium hydroxide there has been very little information available on the $\mathrm{pH}$ of other medicaments like iodoformised calcium hydroxide and Ledermix. Unphysiological pH's are undoubtedly detrimental to the tissues directly in contact. With the medicament, it is suggested that the $\mathrm{pH}$ of endodontic medicaments be considered as an important property in their antibacterial efficacy \& toxicological assessment for their use on vital tissues ${ }^{2}$.

After instrumentation of root canals various fluids such as extracellular fluids, exudates, pus or even saliva may seep into the canal. A sustained high alkalinity in the root canal between appointments may be challenged by ingress of tissue fluids from dentinal tubules, by exudates or by pus from peripaical area. Therefore application of an intracanal medicament that releases a considerable amount of hydroxyl ions and maintains high $\mathrm{pH}$ in the canal space is important. The purpose of this preliminary report is, therefore, to assess in vitro the $\mathrm{pH}$ characteristics of three non-setting calcium hydroxide preparations with \& without contamination of root canals in a simulated periapical environment ${ }^{3}$.

\section{Materials And Method}

One hundred and eight recently extracted mandibular first premolars of similar diameter, length, and taper of roots were selected for the study. The soft tissue remnants on the tooth were removed with a soft brush. The teeth were examined for fractures, cracks, or any other defects. All the teeth were stored in freezer in distilled water until sufficient number of samples was collected. The crowns of teeth were sectioned at the cemento-enamel junction with diamond disk under continuous water spray.

Whole sample size of one hundred and eight teeth was divided into three main groups for three different intracanal medicaments. Thirty six teeth included in each group were randomly divided into three subgroups. Each sub-group has twelve teeth in it. First subgroup (control group): Root canals were filled with calcium hydroxide, Metapex, Ledermix \& calcium hydroxide combination. Second subgroup: Root canals contaminated with $\mathrm{pH} 4$ buffer (simulating pus) and filled with respective medicaments. Third subgroup: Root canals filled with respective medicaments and contaminated periapically with $\mathrm{pH} 4$ buffer.

Uniform access preparations are made with high speed bur. Any remaining pulp tissue extirpated with a barbed broaches. The working length of the root was determined by inserting a no. $15 \mathrm{~K}$-file until it was seen at the apex and then subtracting $1 \mathrm{~mm}$ from its length. The canals were instrumented with a circumferential filing 
technique up to a no. 80 master apical file. After each instrument was used, the canals were irrigated with $1 \mathrm{ml}$ of distilled water. The canals were dried with sterilized paper points. Roots are filled with medicaments. For calcium hydroxide and metapex which comes in premixed paste form in syringes are used for filling the canal. Ledermix and calcium hydroxide with 50 volume\% combination which is mixed thoroughly in glass mortar and pestle is used. Lentulospiral technique is used to fill the canals. While filling the canals, each root was held in a moist gauze pad to prevent the smearing of the medicament on the root and also to maintain the tooth in a moist environment. The access was sealed with reinforced zinc oxide eugenol cement (Kalzinol). For intracanal contamination sub-group $0.05 \mathrm{ml}$ of $\mathrm{pH} 4$ buffer is injected into the canal using an insulin syringe before filling the canals with medicament. For periapical contamination sub-group: a dish containing small depressions into which $0.05 \mathrm{ml}$ of buffer is placed and a paraffin film is stretched over it. Medicament filled roots are suspended for 5minutes through this hole in which only the apical part of the root is in contact with the buffer. Each root was then washed with distilled water before placing it in its respective bottle.

All samples were immersed in $2.5 \mathrm{ml}$ of deionized distilled water which has a $\mathrm{pH}$ of $7.52 \mathrm{in}$ an air tight screw capped glass vials and maintained at $37^{\circ} \mathrm{C}$. All glass vials were suspended in a test tube stand and placed in an incubator to maintain at a constant temperature.

\section{II.1 Measuring the pH:}

The digital $\mathrm{pH}$ meter (ELICO Pvt Ltd, Hyderabad, India) was calibrated to a $\mathrm{pH}$ of $4.02 \& 9.18$ with a standard buffer before use. The $\mathrm{pH}$ was determined by placing the combined $\mathrm{pH}$ electrode into each sample bottle, stirring the solution for 10 seconds and then recording the $\mathrm{pH}$ level. Care was taken to see that the electrode was fully immersed in the solution before taking the readings. In order to standardize the $\mathrm{pH}$ readings for all samples, the electrode remained submerged in the medium for $30 \mathrm{~s}$. After completion of the measurements, the electrode was rinsed with distilled water and dried with sterile tissue paper to ensure that no medicament particles were left behind, as this potentially could interfere with the next reading. The $\mathrm{pH}$ readings taken at different intervals are $0 \mathrm{hr}$, half an hour, 1 hour, 4 hour, day 1, day 2, day 3, day 7

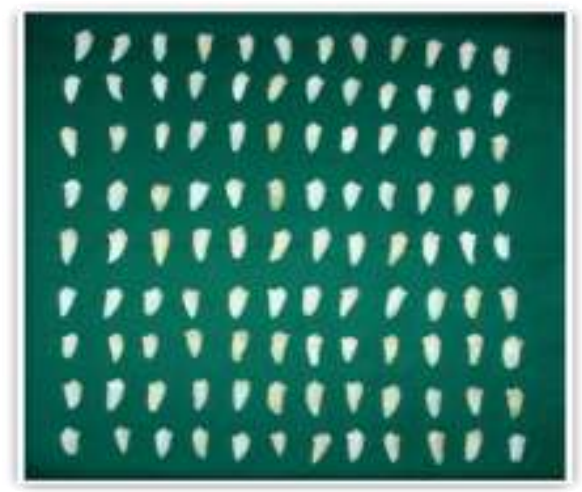

FIG.II : Materials used as intracanal medicaments

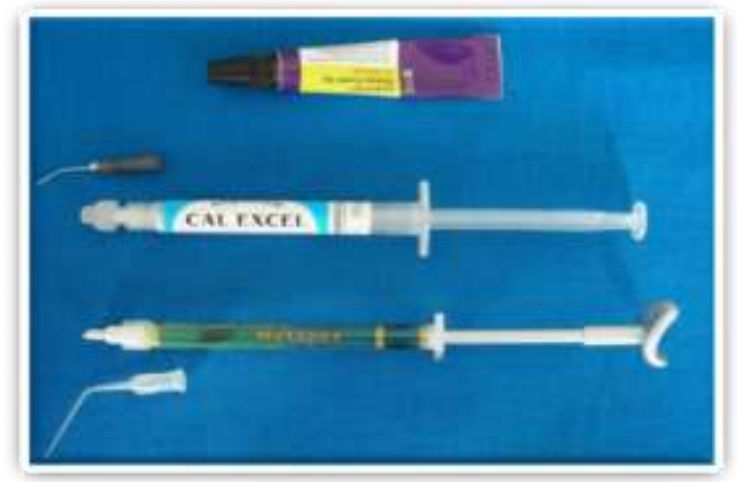

FIG.I: 108 teeth sample of mandibular first premolars

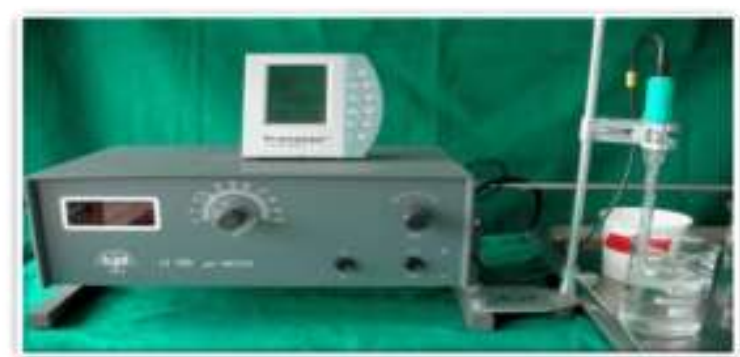

FIG. III: pH Meter (Elico LI 120 model) with combination electrode

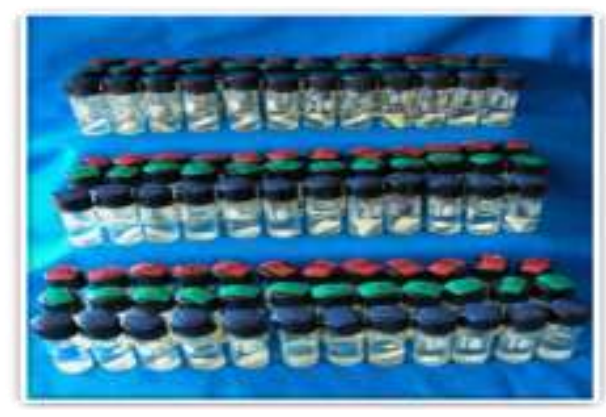



FIG.IV: Total specimens of three subgroups

\begin{tabular}{|c|c|c|c|c|}
\hline \multirow[t]{9}{*}{ Table 1: } & $\mathrm{Ca}(\mathrm{OH})_{2}$ group & \multirow{2}{*}{$\begin{array}{c}\text { Mean } \\
\text { Square }\end{array}$} & \multirow[b]{2}{*}{$F$ value } & \multirow[b]{2}{*}{$P$ value } \\
\hline & Source of variation & & & \\
\hline & $\begin{array}{l}\text { factor1 } \\
\text { factor } 1 * \text { groups }\end{array}$ & $\begin{array}{l}44.431 \\
0.061\end{array}$ & $\begin{array}{l}13370.860 \\
18.274\end{array}$ & $\begin{array}{l}0.000(\mathrm{p}<0.001) \\
0.000(\mathrm{p}<0.001)\end{array}$ \\
\hline & Metapex group & & & \\
\hline & Source of variation & & & \\
\hline & $\begin{array}{l}\text { factor } 1 \\
\text { factor } 1 * \text { groups }\end{array}$ & $\begin{array}{l}11.934 \\
0.060\end{array}$ & $\begin{array}{l}1835.917 \\
9.214\end{array}$ & $\begin{array}{l}0.000(\mathrm{p}<0.001) \\
0.000(\mathrm{p}<0.001)\end{array}$ \\
\hline & $\begin{array}{l}\text { Ledermix\&Ca }(\mathrm{OH})_{2} \\
\text { group }\end{array}$ & & & \\
\hline & Source of variation & & & \\
\hline & $\begin{array}{l}\text { factor1 } \\
\text { factor } 1 * \text { groups }\end{array}$ & $\begin{array}{l}26.397 \\
0.041\end{array}$ & $\begin{array}{l}6090.337 \\
9.544\end{array}$ & $\begin{array}{l}0.000(\mathrm{p}<0.001) \\
0.000(\mathrm{p}<0.001)\end{array}$ \\
\hline
\end{tabular}

Intragroup comparison of $\mathrm{pH}$ values of periapical medium for three intracanal medicaments by repeated measure ANOVA

Table 2: Intergroup comparison of $\mathrm{pH}$ values of periapical medium for three intracanal medicaments by repeated measure ANOVA

\begin{tabular}{|c|c|c|c|}
\hline Control groups & & & \\
\hline Source of variation & $\begin{array}{l}\text { Mean } \\
\text { Square }\end{array}$ & F value & $P$ value \\
\hline $\begin{array}{l}\text { factor } 1 \\
\text { factor } 1 * \text { groups }\end{array}$ & $\begin{array}{l}28.197 \\
1.352\end{array}$ & $\begin{array}{l}6033.465 \\
289.237\end{array}$ & $\begin{array}{l}0.000(\mathrm{p}<0.001) \\
0.000(\mathrm{p}<0.001)\end{array}$ \\
\hline Groups with ICC & & & \\
\hline Source of variation & & & \\
\hline $\begin{array}{l}\text { factor } 1 \\
\text { factor } 1 * \text { groups }\end{array}$ & $\begin{array}{l}22.599 \\
1.296 \\
\end{array}$ & $\begin{array}{l}4186.981 \\
240.149 \\
\end{array}$ & $\begin{array}{l}0.000(\mathrm{p}<0.001) \\
0.000(\mathrm{p}<0.001)\end{array}$ \\
\hline Groups with PAC & & & \\
\hline Source of variation & & & \\
\hline $\begin{array}{l}\text { factor } 1 \\
\text { factor } 1 * \text { groups }\end{array}$ & $\begin{array}{l}24.510 \\
1.246\end{array}$ & $\begin{array}{l}5748.029 \\
292.110\end{array}$ & $\begin{array}{l}0.000(\mathrm{p}<0.001) \\
0.000(\mathrm{p}<0.001)\end{array}$ \\
\hline
\end{tabular}

ICC- Intracanal contamination, PAC- Periapical contamination

\section{Results And Discussion}

The action of calcium hydroxide, that is the hydroxyl ions, is through the dentinal tubules and the apical foramen, with the latter being the most effective. The alkalinity of the periapical tissues that can be achieved by the use of calcium hydroxide compounds and the method of diffusion of hydroxyl ions through the apical foramen is therefore worthy of investigation ${ }^{1}$.

The $\mathrm{pH}$ values of the combinations are likely to be different from the parent medicaments, yet this problem has not been addressed by clinicians. In particular, as antimicrobial activity and hard tissue-inducing effects of calcium hydroxide have been associated with its high $\mathrm{pH}$, loss of this may affect its therapeutic potential $^{2}$.

The importance of the alkalinizing effects of calcium hydroxide products used as intracanal dressings and their capacity to produce hydroxyl ions in the periapical environment has been extensively reported. But the $\mathrm{pH}$ study of dyadic combinations of calcium hydroxide was reported by only one study which was done by $\mathrm{W}$. Kim Seow in 1990.

For the present study it was impossible to obtain fresh sample of pus from a root canal, hence a pH 4 buffer was used because it has been found that the $\mathrm{pH}$ of pus is often acidic (Flynn 1994) ${ }^{3}$. Thomas GH et al used $0.05 \mathrm{ml}$ of saline for moisture contamination of root canal system in an in vitro study. Taking this as reference in this present study $0.05 \mathrm{ml}$ of $\mathrm{pH} 4$ buffer was used for contamination of canals ${ }^{4}$.

Zmener et al in an in vitro study of the $\mathrm{pH}$ of three calcium hydroxide dressing materials used a $17 \mathrm{~mm}$ long glass tubes which were positioned in the center of the vials containing $2.5 \mathrm{ml}$ distilled water and extended $15 \mathrm{~mm}$ into the testing medium, in accordance to this study, for the present study $2.5 \mathrm{ml}$ of distilled water was used to suspend the medicament filled roots ${ }^{1}$. 
Bystrom et al showed that short application of calcium hydroxide dressing in vitro to bacteria commonly found in necrotic cases is very effective. Sundquist et al showed that to ensure continuous $\mathrm{OH}^{-}$ion release over time sufficient to achieve an antibacterial effect, a calcium hydroxide dressing has to be applied in the root canal for a period of 7 days. Panagiotis et al in an in vitro experiment showed that a 5 -day period is adequate for calcium hydroxide pastes to release the hydroxyl ions. Considering the above studies the present study conducted for a 7 day period ${ }^{5}$.

In the present in vitro experiment, the increase of mean $\mathrm{pH}$ value of calcium hydroxide was gradual from $7.50 \pm 0.02$ to 11.23 for 7 days. Panagiotis GB et al 1997 demonstrated that the $\mathrm{pH}$ changes of calcium hydroxide (tempcanal) rose rapidly within a day and reached peak on $5^{\text {th }}$ day $(11.30$ to 12.38$) .{ }^{13}$ Robert GH et al 2005 showed that hydroxyl ion release of calcium hydroxide (pulpdent) within a day depending on the aperture size for 80 was $10.25^{6}$.

Results of the present study did not agree with those from previous studies. This difference may be caused by the different methodologies used. The above mentioned studies did not use in prepared root canals of extracted human teeth, but to simulate the natural condition, pipette tips, or direct mixture of the test material in distilled water. Another factor that may have affected the results is that in natural human teeth the buffering effect of dentin plays an important role. When using glass tubes this issue is entirely non-existent ${ }^{1}$.

Intracanal contamination and periapical contamination with $\mathrm{pH} 4$ buffer, did affect the rise of $\mathrm{pH}$ at all intervals. Compared to intracanal contamination periapical contamination with calcium hydroxide group had initial rise in $\mathrm{pH}$ better than intracanal contamination group

The reason might be the study design in which suspending the root specimens into the large volume of periapical medium might have diluted the effect of the $\mathrm{pH} 4$ buffer which could not have affected the much of the hydroxyl ion releasing potential of the calcium hydroxide. But calcium hydroxide had tried to overpower the original $\mathrm{pH} 4$ buffer and would take a more period than without any contaminations. This is in accordance with the study conducted by Larsen \& Bindslev (2000) showed that, slurry of pure calcium hydroxide and calcicur (commercial paste) had overcome the $\mathrm{pH} 4$ buffer effect but the rise in $\mathrm{pH}$ compare to saline was not as rapid as with saline ${ }^{3}$.

As compared to calcium hydroxide Metapex showed the maximum rise till 9.45 only, this is because the content of calcium hydroxide is only a 30\% and Metapex paste has oil based vehicle. Oily vehicles are nonwater-soluble substances that promote the lowest solubility and diffusion of the paste within the tissues. Pastes containing this kind of vehicle may remain within the root canal for longer than the pastes containing aqueous or viscous vehicles ${ }^{7}$ various studies have demonstrated that water is an effective carrier for calcium hydroxide, producing a rapid dissociation of hydroxyl and calcium ions ${ }^{6}$.

Flaviana Bombarda et al (2004) reported that LC paste (oil based $\left.\mathrm{Ca}(\mathrm{OH})_{2}\right)$ was in capable of alkalinizing the medium (5.6 to 6.5 in $72 \mathrm{hrs}$ ).

The mean change in $\mathrm{pH}$ value of periapical medium for Ledermix \& calcium hydroxide group from 0 hr to 7 day was 7.49 to 10.67.The present study results are not in agreement with the study conducted by Anderson \& Seow (1990). They described that combination of $50 \mathrm{vol} \%$ of Ledermix with calcium hydroxide did not significantly affect the $\mathrm{pH}$ of calcium hydroxide $(12.06 \pm 001)$. This difference may be caused by the different methodology used in the previous study, Anderson showed that the $\mathrm{pH}$ of the material directly. The $\mathrm{pH}$ of Ledermix was $8.13 \pm 0.01$ as demonstrated by Anderson ${ }^{2}$.

In the present study while mixing the Ledermix and calcium hydroxide which is exposed to the air might have affected the $\mathrm{pH}$ of calcium hydroxide, when calcium ions come into contact with carbon dioxide, or carbonate ions, calcium carbonate is formed (Holland et al 1979). This material has a very low solubility, and has neither biological nor antibacterial properties (Estrela 1994) ${ }^{8}$.

A study conducted by Gordon et al (1985) to observe the effect of calcium hydroxide solutions with different $\mathrm{pH}$ values on connective tissue, indicate that a mildly alkaline environment is necessary for the optimum action of alkaline phosphatase ${ }^{9}$. In an vitro study by Lengheden (1994) on the influence of $\mathrm{pH}$ and calcium ion on growth and attachment of human fibroblasts, it was observed that at $\mathrm{pH}$ levels above 7.8 both attachment and growth decreased significantly which are necessary for periodontal tissue healing. However, one must keep in mind that the conditions of cell cultures in vitro, in particular when cells are in direct contact with calcium hydroxide, do not adequately reflect the in vivo situation. In a clinical case, the root canal has to be filled with calcium hydroxide and the presence of a high $\mathrm{pH}$ in periapical tissues for a prolonged period of time is unlikely to occur, because of the buffering effect of dentin and/ or the dilution effect of connective tissue serum. Additional buffering may also be expected from the high solubility of calcium hydroxide preparations as well as from the acidification process by inflammatory cells ${ }^{1}$.

Intracanal placement of a non setting calcium hydroxide paste is a common endodontic practice. The selection of a dyadic combination to get combined putative effect of the medicaments has not been made on a sound scientific basis. This in vitro study of the rise of $\mathrm{pH}$ from combination of calcium hydroxide endodontic medicaments indicates that dyadic combinations can have a profound influence on the hydroxyl ion release for initial period. 
Within the limitations of this experimental design, definitive conclusions cannot be drawn and further in vivo investigations are needed to establish a correlation between the incremental increase and duration in $\mathrm{pH}$ and the biological response of the periapical tissues.

Graph I: Intergroup comparison of mean $\mathrm{pH}$ values of three medicaments for control groups

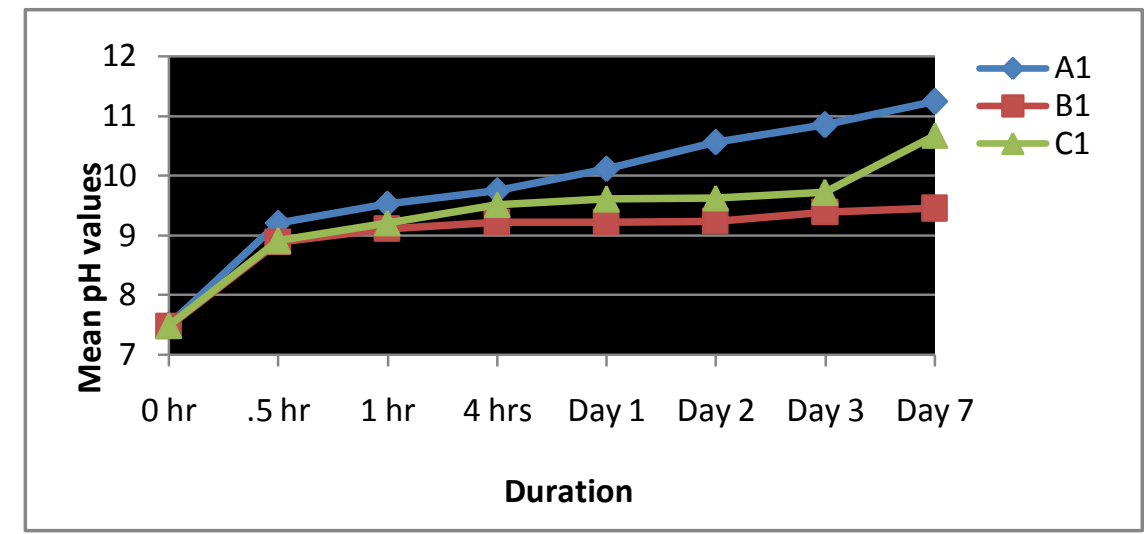

$\mathrm{A} 1-\mathrm{Ca}(\mathrm{OH})_{2}, \quad$ B1-Metapex, $\quad$ C1- Ledermix \&Ca(OH$)_{2}$

Graph II:Intergroup comparison of mean $\mathrm{pH}$ values of three medicaments with intracanal contamination

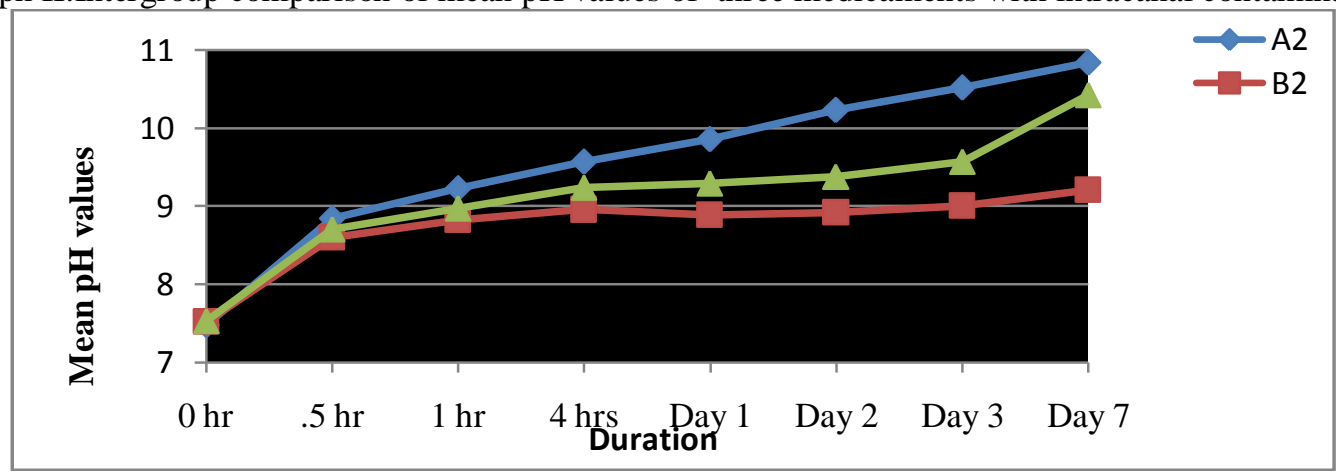

A2- $\mathrm{Ca}(\mathrm{OH})_{2}+\mathrm{ICC}, \quad$ B2-Metapex + ICC, C2- Ledermix \&Ca(OH$)_{2}+\mathrm{ICC}$

Graph III:Intergroup comparison of mean $\mathrm{pH}$ values of three medicaments with periapical contamination

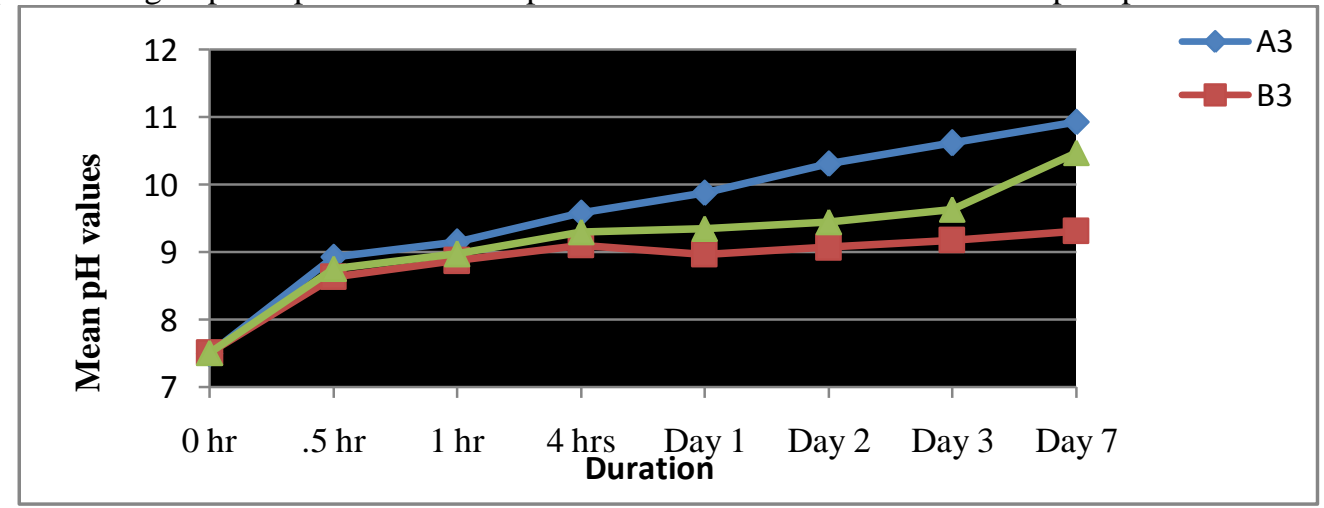

A3- $\mathrm{Ca}(\mathrm{OH})_{2}+\mathrm{PAC}, \quad$ B3-Metapex + PAC,$\quad$ C3- Ledermix\&Ca $(\mathrm{OH})_{2}+\mathrm{PAC}$

IV. Conclusion

1) It was found that a paste of calcium hydroxide produced a consistently higher rise in $\mathrm{pH}$ than Metapex \& Ledermix \& calcium hydroxide combination over a period of one week.

2) Calcium hydroxide paste has a greater hydroxyl releasing potential than calcium hydroxide combination medicaments and may therefore be an effective choice in clinical practice where seepage of pus into the root canal between appointments.

3) Intracanal contamination with $\mathrm{pH} 4$ buffer has a profound effect on the initial rise in $\mathrm{pH}$ of calcium hydroxide and combination medicaments than the periapical contamination.

4) Contaminations of root canals with lower $\mathrm{pH}$ substance significantly affect the normal rise in $\mathrm{pH}$ of medicament 


\section{References}

[1]. Zmener O, Pameijer CH, Banegas G. An in vitro study of the pH of three calcium hydroxide dressing materials. Endod Dent Traumatol 2007; 23: 21-25.

[2]. Anderson M, Seow WK. The pH of endodontic medicaments used in pediatric dentistry. Effects of dyadic combination. J Clin Pediatr Dent 1990; 15: 42-45.

[3]. Larsen MJ, Horsted-Bindsle P. A laboratory study evaluating the release of hydroxyl ions from various calcium hydroxide products in narrow root canal like tubes. Int Endod J 2000; 3: 238-42.

[4]. Horning GT, Kessler JR. A comparison of three different root canal sealers when used to obdurate moisture contaminated root canal system. J Endod 1995; 21: 354-57.

[5]. Beltes PG, Pissiotis E, Koulaouzidou, Kortsaris AH. In vitro release of hydroxyl ions from six types of calcium hydroxide non setting pastes. J Endod 1997; 23: 413-15.

[6]. Robert GH, Liewehr FR, Buxton TB, Mcpherson JC. Apical diffusion of calcium hydroxide in an in vitro model. J Endod 2004; 31 : 57-60.

[7]. Fava LRG, Saunders WP. Calcium hydroxide pastes classification and clinical indications. Int Endod J 1999; 32: 257-282.

[8]. Kwon TY, Fujishima T, Imai Y. FT-Raman spectroscopy of calcium hydroxide medicament in root canals. Int Endod J 2004; 37 : 489-93.

[9]. Simon ST, Bhat KS, Francis R. Effect of four vehicles on the $\mathrm{pH}$ of calcium hydroxide and the release of calcium ion. Oral Surg Oral med Oral Pathol Oral Radiol Endod 1995; 80: 459-64.

[10]. Amanda Law, Harold Messer. An evidence based analysis of the antibacterial effectiveness of intracanal medicaments. J Endod 2004; 30: 689-94.

[11]. Farhad A, Esfahan ZM. Calcium hydroxide a review. Int Dent J 2005; 55: 293-301.

[12]. Ferreira FBA, Silva E Souza PAR, Vale MS, Moraes IG, Granjeiro JM. Evaluation of pH levels and calcium ion release in various calcium hydroxide endodontic dressings. Oral Surg Oral Med Oral Pathol Oral Radiol Endod 2004; 97: 388-92.

[13]. Stephen JC etal. Dentinal tubule disinfection using three calcium hydroxide formulations. J Endod 2005; $31: 50-52$.

[14]. Thong YL, Messer HH, Siar CH, Saw LH. Periodontal response to two intracanal medicaments in replanted monkey incisors. Dental Traumatology 2001; 17: 254-59.

[15]. Siqueira JF, Uzeda MD. Intracanal medicaments: Evaluation of the antibacterial effects of chlorhexidine, metronidazole, and calcium hydroxide associated with three vehicles. J Endod 1997; 23: 167-69. 